\title{
EXPERIMENTAL INVESTIGATION OF THE TRANSITION ZONE OF AIR-STEAM MIXTURE JETS INTO STAGNANT WATER
}

\author{
YAISEL CÓRDOVA ${ }^{1,2}$, DAVID BLANCO ${ }^{1}$, CÉSAR BERNA $^{1}$, JOSÉ LUIS MUÑOZ-COBO ${ }^{1}$, \\ ALBERTO ESCRIVÁ $^{1}$ \& YAGO RIVERA ${ }^{1}$ \\ ${ }^{1}$ Instituto de Ingeniería Energética, Universitat Politècnica de València, Spain \\ ${ }^{2}$ Instituto Superior de Tecnologías y Ciencias Aplicadas, Cuba
}

\begin{abstract}
The phenomenon of direct contact condensation of steam into pools with subcooled water is of great interest for various industrial applications, allowing rapid condensation of steam by providing high heat transfer and mass exchange capacity. For the nuclear industry it is of great interest to understand steam condensation in the presence of non-condensable (NC) gases from the point of view of passive safety of nuclear power plants. Currently there are several experimental studies related to steam and noncondensable gas discharges in pools, but work is still in progress to obtain a wider range of information. The objective of the present study is to characterize the horizontal jet behavior in the transition zone, when initially steam is being discharged and then a small fraction of air is injected. An abrupt change in behavior is observed when a jet dominated totally by momentum forces experiences the impulse of buoyancy forces induced by the non-condensable gases. This phenomenon is due to the deterioration of heat transfer caused by the presence of air. This fact limits condensation by direct contact and modifies the trajectory of the submerged gases. Direct visualization techniques using a high-speed camera and image processing methods are used to characterize this jet behavior. Different tests have been performed by varying the steam flow rate, pool water temperature and nozzle diameter. In each of the tests, the air flow rate required for the transition zone to occur was determined. The processing of the obtained images is performed by means of a multi-step subroutine in MATLAB. Experimental results showed that the water temperature and nozzle diameter play an important role in the transition zone from the pure jet to the steam-air mixture jet.
\end{abstract}

Keywords: non-condensable gas, steam, direct contact condensation, jets, two-phase flow, digital image processing.

\section{INTRODUCTION}

Direct contact condensation of a steam jet discharged into a water pool allows a high capacity for mass, momentum, and energy exchange from steam to water. In the industry this phenomenon is widely used, an example is the pressure suppression pool, which provides a heat sink during the actuation of the safety-relief valves, condensing the steam that may be released in the drywell during a leak or loss-of-coolant accident (LOCA), causing a rapid decrease in pressure [1]-[3].

Previous research to characterize the behavior of the steam jet has been divided into three main areas: evaluation of the shape and steam plume length, estimation of the mean heat transfer coefficient, and the development of map characterizing the condensation regime. As a summary of the contribution of these investigations, they have defined three different steam plume shapes (i.e., conical, ellipsoidal, and divergent shapes). Kerney et al. [4] development a correlation for estimating the steam plume penetration length considering a constant Stanton number (for choked injector flows), based on the effect of injector diameter, flow rate and pool temperature. Many researchers [5]-[7] built on the results obtained by Kerney and extended the ranges of experiments by considering different working fluids, flow rates and pressures. Based on pool water temperature and steam mass velocity, different regime 
maps were developed for low steam mass flow [8] and high steam mass flows [7]. There are several maps of steam condensation regimes in the literature. One of the most important [9] has six defined regions leading to six defined regions (i.e., Chugging (C), Transition Chugging (TC), Oscillatory Condensation (CO), Bubble Oscillatory Condensation (BCO), Stable Condensation (SC), Interfacial Oscillatory Condensation (IOC) and Non-apparent Condensation (NC)).

The measurement techniques for the study of the interface behavior are quite complex, as the interface has a highly unstable behavior. Visualization-based techniques are widely used in the study of different phenomena associated with two-phase flow. It is possible to study the trajectory of the jet, its contour, its breakup in the form of bubbles and the behavior of these bubbles. These techniques can be divided into two main groups: direct visualization techniques [10]-[24] and advanced visualization techniques [2], [25], [26]. The first is the most used and usually involves cameras incorporating charge-coupled devices (CCD) and illumination systems and the second is more complex experimentally, where laser systems are usually used as the illumination source.

As show above, previous studies have focused on the behavior of the jet discharged only of steam and very few researchers have studied steam and non-condensable gas discharges due to their complexity. In this work we will focus on characterizing the behavior that occurs when steam is discharged into subcooled water through a nozzle and a quantity of NC gas appears and how it affects the behavior of the jet.

\section{EXPERIMENTAL MATERIAL AND METHODS}

\subsection{Experimental facility}

The experimental installation allows the discharge of jets of steam and air mixture into a pool with subcooled water by using two lines. The pool is rectangular with dimensions (length $x$ width $\times$ height) of $1,500 \mathrm{~mm} \times 500 \mathrm{~mm} \times 600 \mathrm{~mm}$ and all its walls are made of glass which allows optical measurements. The water used for both the pool and to generate steam is treated by a reverse osmosis process where all impurities and dissolved lime are removed. The water level in the pool is maintained at $500 \mathrm{~mm}$ and the rest of the pool height $(100 \mathrm{~mm})$ is considered as free surface. Fig. 1 shows in detail a schematic diagram of the two lines (steam and air), each of the equipment present in the installation, and the geometrical characteristics of the discharge pool.

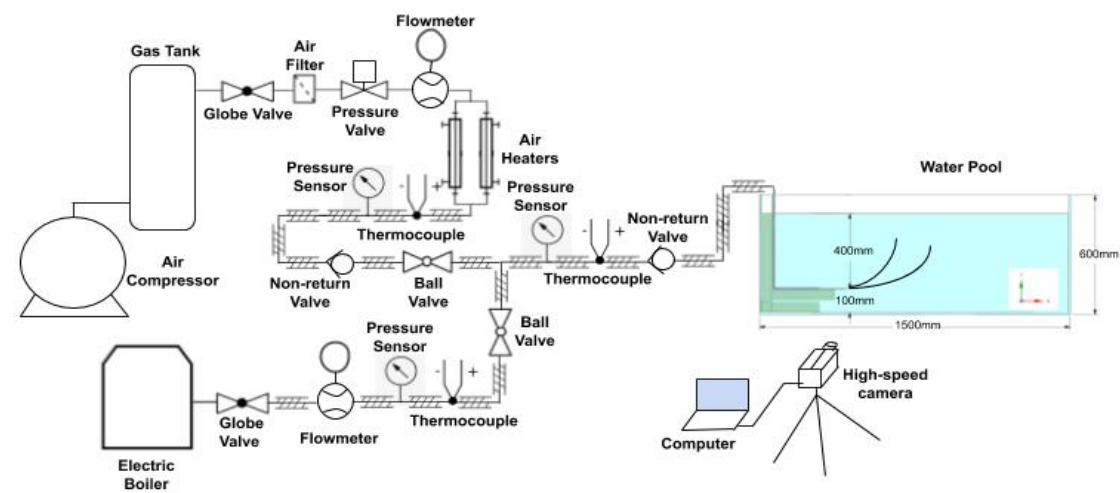

Figure 1: Schematic diagram of the experimental facility [27]. 
Saturated steam is obtained by an electric steam generator operating at a pressure of 6 bar. The steam volumetric flow is measured by a rotameter with an operating range of 20 to $110 \mathrm{l} / \mathrm{min}$ and a flowmeter with an operating range of 50 to $400 \mathrm{l} / \mathrm{min}$. Downstream, a thermocouple and a pressure sensor record the parameters before the mixing zone.

The air supply line is fed by a screw air compressor with a capacity of $1,420 \mathrm{l} / \mathrm{min}$ and 10 bars of maximum operating pressure. The air is stabilized in a gas tank (boiler), which allows a better control of the discharge conditions by means of a globe valve and a precision valve. Downstream, a flowmeter allows to know the air flow rate to be discharged. Two heaters in parallel of $120 \mathrm{~V}$ and $500 \mathrm{~W}$ are installed to maintain the air temperature above the steam temperature upstream of the mixing zone to avoid condensation of the steam. The power of each heater is controlled by a power module, a closed-loop PID control system and a thermocouple used as set point. As in the steam line, a thermocouple and a pressure sensor are installed upstream of the mixing zone. To guarantee that air is perfectly mixed with the steam, the mixing line is sufficiently long enough before discharge.

To know the jet discharge parameters, a pressure sensor and a thermocouple are placed before the nozzle outlet. All sensors are connected to a National Instruments data acquisition system (Model 6259 16-bit) driven by Labview Software to monitor and control data acquisition.

The hoses are made of a flexible material that withstands temperatures up to $232^{\circ} \mathrm{C}$ and a pressure of 18 bar, additionally they are thermally insulated to avoid losses in the areas where the working fluids are not at room temperature.

The jet behavior is recorded by a high-speed camera (PCO.1200 hs model) with a shooting frequency of 636 frames per second (fps) at high resolution $(1,280 \times 1,024$ pixel). To provide the necessary light for the high-speed camera, an LED light panel with dimensions $1,200 \mathrm{~mm} \times 600 \mathrm{~mm}$ was placed at the back of the pool. Fig. 2 shows a photo taken of experimental facility.

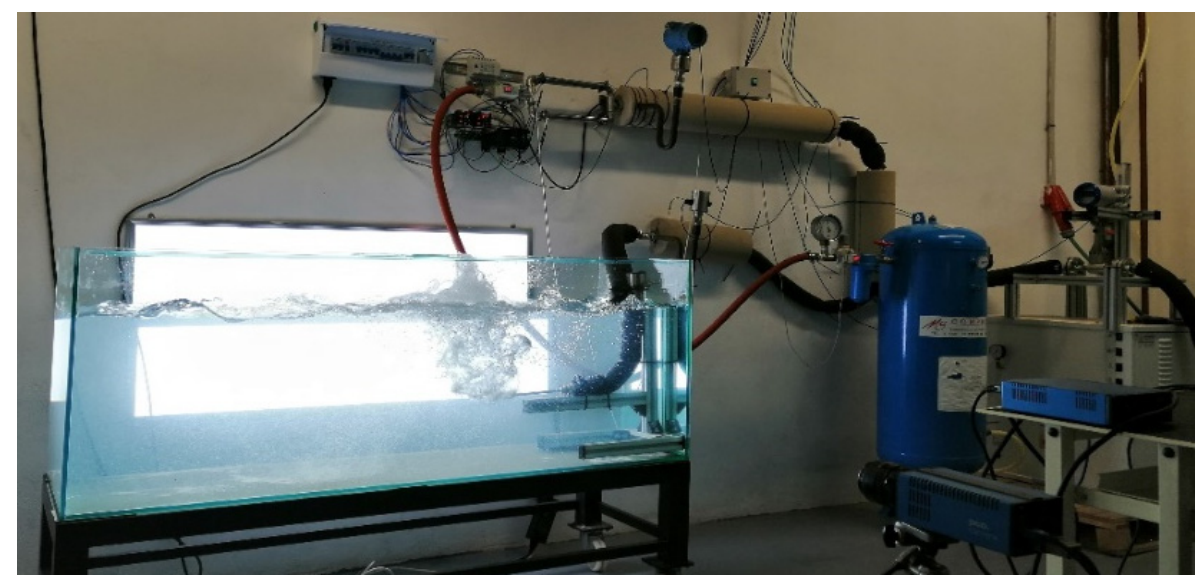

Figure 2: Experimental facility [27].

\subsection{Test matrix}

For this test matrix, five interchangeable stainless-steel nozzles were used. For each steam flow rate, it was analyzed what would be the percentage of air in which it would change from 
a jet dominated only by the force of the momentum to a jet where buoyancy forces dominated, and a continuous curved jet would appear. The test matrix used is summarized in Table 1.

Table 1: Summary of experimental initial conditions.

\begin{tabular}{lc}
\hline \hline Parameters & Value \\
\hline \hline Nozzle diameter & $2-6 \mathrm{~mm}$ \\
Steam volumetric flux & $30-201 / \mathrm{min}$ \\
Water temperature & $25-60^{\circ} \mathrm{C}$ \\
\hline \hline
\end{tabular}

\subsection{Image analysis method}

To capture the change of the jet behavior where initially there is steam until the necessary air flow is obtained where it is determined that it is a continuous jet, it is necessary to make a series of images at different percentages of air flow using the direct visualization technique by means of a high-speed camera (CCD). The method of analysis of the images has several steps. First, a background image showing only the nozzle is recorded to determine the number of pixels per millimeter as a function of the external diameter of the nozzle. Then, the discharge is recorded for each of the initial conditions defined for that nozzle. All images had a resolution of $1,024 \times 1,280$ pixels. According to the setting parameters defined in the camera software and the size of the RAM memory, the maximum number of images in each of the recordings of the jet discharge was 1,200 images.

The processing of these images is performed by means of a MATLAB script. The image of the jet discharge is cropped to the same size as the background image, eliminating the part that is not interesting for our study. The image in grayscale is then binarized using a specified threshold. Next, a function performs the median filtering of the image, where each output pixel contains the median value in a 3 by 3 neighborhood around the corresponding pixel. Because there are areas of the gas jet composed of some shades is applied a function for fills the holes in the input binary image. In this syntax, a hole is a set of background pixels that cannot be reached by filling in the background from the image edge (see Fig. 3(d)). Subsequently, the adjustment (morphological) operation is applied to remove small bubbles from the image, for these operations two functions are used; the first erodes the binary image and the second dilates the binary image, these functions use a disk-shaped structuring element with a radius $r=6$ (see Fig. 3(e)). Finally, a function that returns a binary image that contains only the perimeter pixels of objects in the input image. A pixel is part of the perimeter if it is nonzero, and it is connected to at least one zero-valued pixel (see Fig. 3(f)).
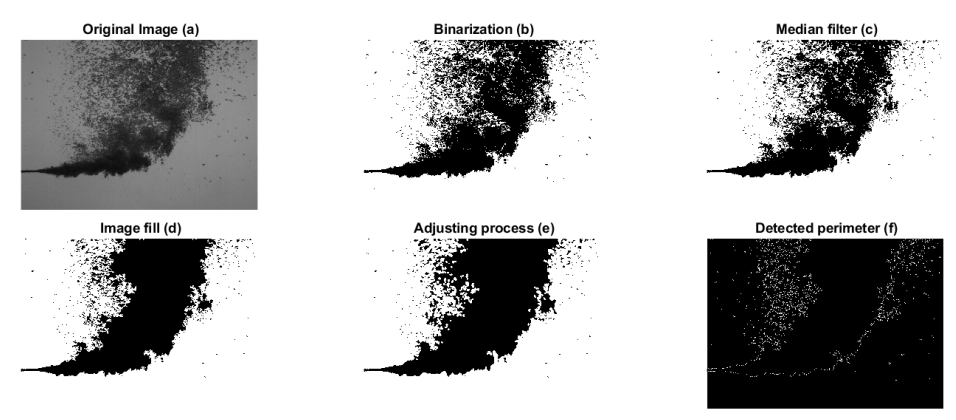

Figure 3: Steps used in the routine implemented in MATLAB to detect the jet boundary. 


\section{EXPERIMENTAL RESULTS AND DISCUSSION}

Discharges in the form of steam jets are characterized by a practically horizontal trajectory until their extinction, behavior caused by the phenomenon of direct condensation due to the presence of water around them. While the incondensable jets present a typical curved shape, due to the balance between inertial forces and buoyancy forces. Taking these two behaviors as a premise, the present work aims to analyze how the transition between these two structures takes place. For this purpose, a progressively larger amount of non-condensable gases is introduced to a pure steam jet (Fig. 4). The main objective of this study is to determine the experimental conditions under which the transition takes place, i.e., the shape changes from a pure steam jet to a continuous jet that reaches the free sheet. Direct visualization techniques have been used to carry out this study.

Fig. 4 shows the jet behavior in each of the cases with different air fractions $\left(\mathrm{V}_{\mathrm{a}}\right)$, taking one of the 1,200 subsequent images of each discharge series. At the first moment, when only steam was discharged (i.e., $\mathrm{V}_{\mathrm{s}}=1$ and $\mathrm{V}_{\mathrm{a}}=0$ ), the jet was barely perceptible because everything was condensing, and the momentum force predominated up to its extinction. At the beginning of the air discharge, after the air-line pressure was sufficient for the air flow to be perceptible in the jet behavior, it was possible to appreciate how some bubbles rose randomly, appearing the buoyancy phenomenon. Then, as the air volumetric fraction was increased, it can be seen how the behavior of the discharge changed from isolated bubbles to a defined steam/air-water interface.

Fig. 4 also shows how the behavior of the discharge goes from a steam condensation regime, in this case of study it was $\mathrm{SC}$ regime, to a regime of isolated air bubbles appearing and detaching from the jet and finally reaching the air jet regime where the buoyancy force dominates, which is because the disturbances move across the phase boundary faster than they can accumulate as noted by Liang et al. [28]. An important finding is that the transition to continuous buoyant jet does not always take place in the same way; for low flows, the transition is quite abrupt while for high flows it is more progressive.
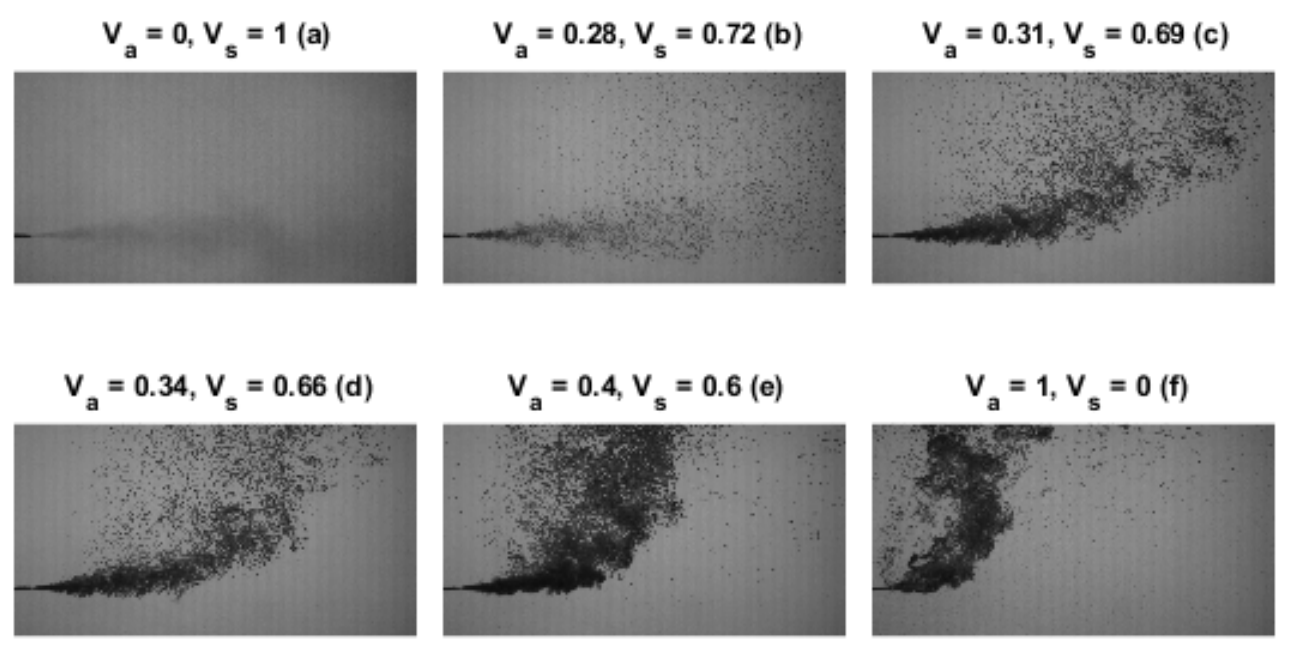

Figure 4: Images obtained for $3 \mathrm{~mm}$ diameter with different air volume fractions $\left(\mathrm{V}_{\mathrm{a}}\right)$ to determine the range where the transition could occur, starting from steam volume fraction $\left(\mathrm{V}_{\mathrm{s}}\right)$ of 1 . 


\subsection{Image of variable spatial intensity and contours}

A summation method was applied to the images processed in MATLAB, in which each processed image was added to the last one until 1,200 images in each series were reached, obtaining an image with varying spatial intensity (defined by the number of images in each subsequent image series). The colors indicate how many times in all images a certain place in the field of view is occupied by gas or water. As can be seen in Fig. 5, the steam where it can be captured the most is just after the nozzle exit, the trace after that cannot be captured due to the condensation that prevents having a defined interface between the steam and the gas. Then with the increase of the air fraction the rigidity of the steam plume weakens and brings about that the volume of steam bubbles separated from the steam plume increases, which agrees with the previous results of Zhao et al. [29].
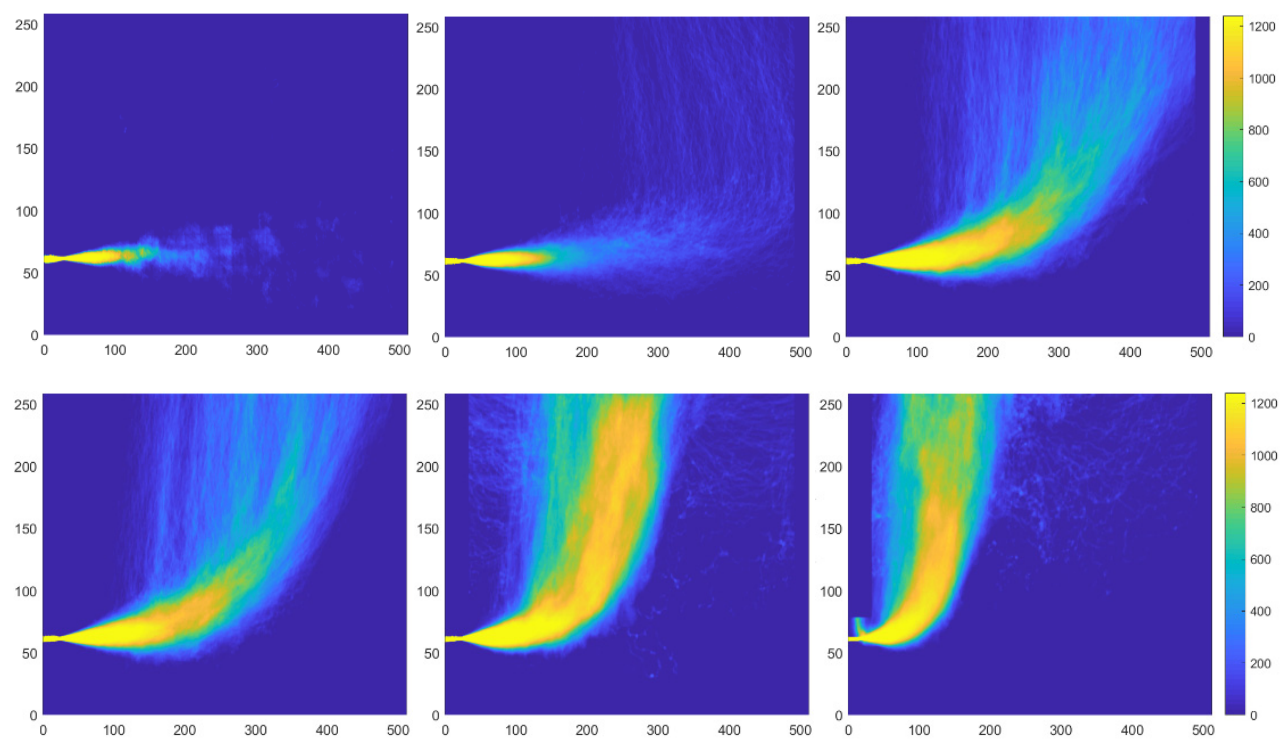

Figure 5: Images of variable spatial intensity obtained for $3 \mathrm{~mm}$ diameter with different air volume fractions.

Fig. 5(c) and (d) show a more defined plume where a more noticeable curvature is already present, but as can be seen the steam/air jet does not reach the free surface in all images due to the pinch-off phenomenon. In addition, the steam/air plume lengthens, and the gas-water interface expands, which is in agreement with that proposed by $\mathrm{Xu}$ [30]. The transition zone was defined as the spatial intensity image in which there was continuity of the jet from the nozzle exit to the free surface and the pinch-off did not appear in the whole series of the processed images (Fig. 5(e)).

To show more clearly where both gas and water are located, the variable spatial intensity image in Fig. 5 is delimited by filled contour isolines (Fig. 6). These isolines delimit the different levels, in this case 6 levels were used, representing in yellow the area where the gas is in most of the images. In these images it can be seen how the large amount of steam that was at the outlet of the nozzle and formed the steam cavity will be dragged by the air current. 
As can be seen in the figures when we had a considerable amount of air, the gas-water interface expanded sharply, and the mixture layer thickened. The air layer at the interface prevented the direct contact condensation by increasing the condensation resistance, which corroborates the work of Xiaoping et al. [31].
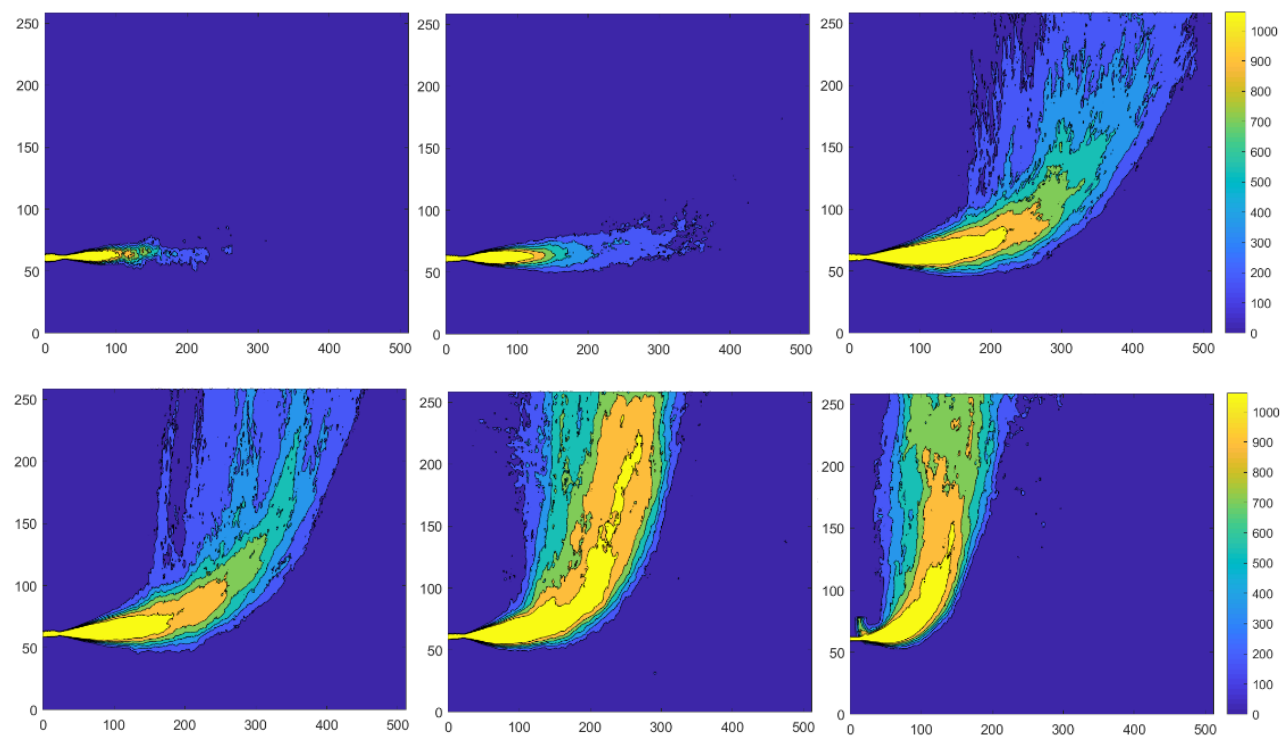

Figure 6: Images of filled contour isolines obtained for $3 \mathrm{~mm}$ diameter with different air volume fractions.

\subsection{Dependence of the velocity on air volumetric fraction}

For the same nozzle diameter, the influence of velocity on the air volumetric fraction required to reach the transition was studied. As can be seen in Fig. 7, velocity was not found to influence the air volume fraction, i.e., there is not most influence of the mass flow rate. This is believed to be because there are several phenomena that counteract each other and do not have a predominant one. For example, as the velocity increases, there is a greater initial expansion (since there is a higher inlet pressure, then a more abrupt expansion has to occurs to equalize its pressure with that of the surrounding medium), consequently a more superheated steam, which makes condensation more difficult and facilitates that a smaller amount of air is able to pull the steam, causing a continuous upward plume to form; but at the same time, there is a greater expansion angle and a higher degree of turbulence which causes greater heat transfer, favoring the steam condensation.

\subsection{Dependence of the cross-sectional area on air volumetric fraction}

An important point that was investigated was how the cross-sectional area for each of the nozzles affected the air volume fraction. As can be seen in Fig. 8, as the diameter increases and with it the cross-sectional area, a lower percentage of air is needed to reach the transition, as shown in the previous section there is not a clear influence of the mass flow rate of steam 


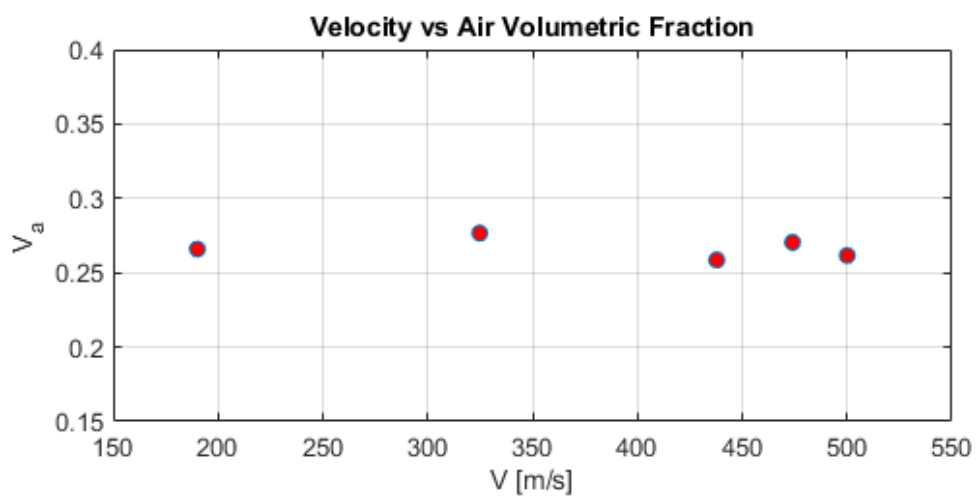

Figure 7: The effect of velocity on air volumetric fraction for $3 \mathrm{~mm}$ diameter nozzle.

discharged. As possible explanation for this tendency could be because when there is a presence of mixed flows of two gases (steam/non-condensable gases), as the steam condense in the gas/liquid interface then consequently there is a tendency of the non-condensable to concentrate in this region, these non-condensable gases deteriorate the heat transfer. Despite of the major proportion of non-condensable gases in smaller nozzle diameter to reach the transition the absolute value of this non-condensable gases is higher in the nozzles of bigger diameter.

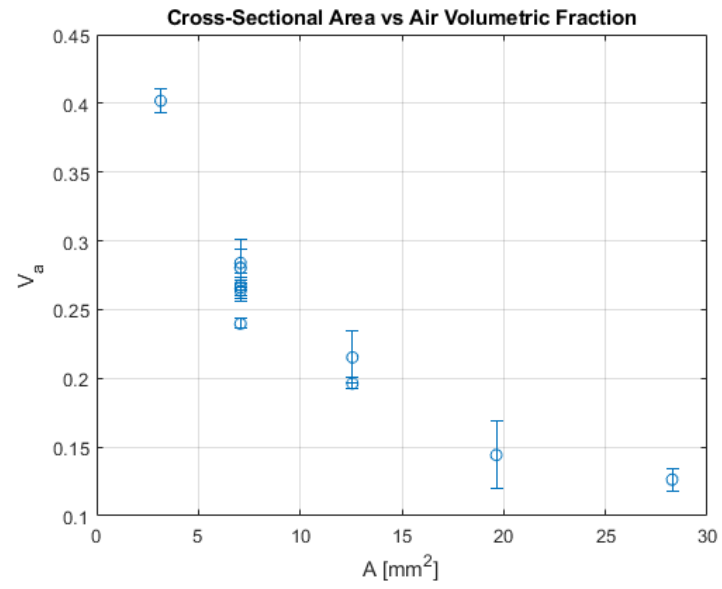

Figure 8: The effect of cross-sectional area on air volumetric fraction for all nozzles diameters.

\section{CONCLUSIONS}

The behavior of steam discharge in stagnant water when air is injected into it is experimentally investigated and it is determined when the transition from steam jet to rising plume jet occurs. The main conclusions obtained are:

1. The variable spatial intensity image obtained for each of the cases allowed determination of the range of air volumetric fraction necessary for the transition to occur. 
2. No dependence on increasing velocity was obtained that would bring an abrupt change in air volume fraction for the same diameter.

3. A dependence between nozzle cross-sectional area and air volume fraction was obtained, i.e., as the cross-sectional area increased, a smaller air volume fraction was necessary to obtain the transition, independent of the mass flow rate of steam discharged.

\section{FUTURE WORKS}

Due to the fact that this work is a first approach to the subject of the transition from pure steam discharge to rising plume discharge, it will be considered for future work to perform a greater number of tests to expand the data base, where a greater number of discharge velocities, various pool water temperatures, nozzle diameters, etc. will be taken into account. It is also considered to study the contribution of other variables in this phenomenon and to obtain a correlation of some parameters such as air volume fraction, expansion angle, nozzle diameter and pool water temperature.

\section{ACKNOWLEDGEMENTS}

The authors are indebted to the support of the Spain plan of I + D support to the EXMOTRANSIN project ENE2016-79489-C2-1-P and the Santiago Grisolía Program for its training research personnel.

\section{REFERENCES}

[1] Norman, T.L. \& Revankar, S.T., Jet-plume condensation of steam-air mixtures in subcooled water, part 1: Experiments. Nucl. Eng. Des., 240(3), pp. 524-532, 2010.

[2] Song, D., Experimental and numerical investigation of thermal stratification by direct contact condensation of steam in pressure suppression pool. The University of Tokyo, 2014.

[3] Rassame, S. et al., Experimental investigation of void distribution in suppression pool during the initial blowdown period of a loss of coolant accident using air-water twophase mixture. Ann. Nucl. Energy, 73, pp. 53-67, 2014.

[4] Kerney, P.J., Faeth, G.M. \& Olson, D.R., Penetration characteristics of a submerged steam jet. AICHE J., 18(3), pp. 548-553, 1972.

[5] Weimer, J.C., Faeth, G.M. \& Olson, D.R., Penetration of vapor jets submerged in subcooled liquids. AICHE J., 19(3), pp. 552-558, 1973.

[6] Kim, Y.S., Park, J.W. \& Song, C.H., Investigation of the stem-water direct contact condensation heat transfer coefficients using interfacial transport models. Int. Commun. Heat Mass Transf., 31(3), pp. 397-408, 2004.

[7] Chun, M.-H., Kim, Y.-S. \& Park, J.-W., An investigation of direct condensation of steam jet in subcooled water. Int. Commun. Heat Mass Transf., 23(7), pp. 947-958, 1996.

[8] Chan, C.K. \& Lee, C.K.B., A regime map for direct contact condensation. Int. J. Multiph. Flow, 8(1), pp. 11-20, 1982.

[9] Cho, M.K., Song, S., Park, C.H., Yang, C.K. \& Chung, S.K., Experimental study on dynamic pressure pulse in direct contact condensation of steam jets discharging into subcooled water. NTHAS98 1. Korea-Japan Symp. Nucl. Therm. Hydraul. Saf., 1998.

[10] Shi, H.H., Wang, B.Y. \& Dai, Z.Q., Research on the mechanics of underwater supersonic gas jets. Sci. China Physics. Mech. Astron., 53(3), pp. 527-535, 2010.

[11] Harby, K., Chiva, S. \& Muñoz-Cobo, J.L., An experimental investigation on the characteristics of submerged horizontal gas jets in liquid ambient. Exp. Therm. Fluid Sci., 53, pp. 26-39, 2014. 
[12] Li, W., Wang, J., Sun, Z., Zhou, Y., Liu, J. \& Meng, Z., Experimental investigation on thermal stratification induced by steam direct contact condensation with noncondensable gas. Appl. Therm. Eng., 154, pp. 628-636, 2019.

[13] Li, W., Wang, J., Zhou, Y., Sun, Z. \& Meng, Z., Investigation on steam contact condensation injected vertically at low mass flux: Part I pure steam experiment. Int. J. Heat Mass Transf., 131, pp. 301-312, 2019.

[14] Xu, Q., Liu, W., Li, W., Yao, T., Chu, X. \& Guo, L., Experimental investigation on interfacial behavior and its associated pressure oscillation in steam jet condensation in subcooled water flow. Int. J. Heat Mass Transf., 145, 2019.

[15] Jo, B., Erkan, N. \& Okamoto, K., Richardson number criteria for direct-contactcondensation-induced thermal stratification using visualization. Prog. Nucl. Energy, 118, 2020.

[16] Xu, Q., Li, W., Chang, Y., Yu, H. \& Guo, L., A quantification of penetration length of steam jet condensation in turbulent water flow in a vertical pipe. Int. J. Heat Mass Transf., 146, 2020.

[17] Qu, X.H., Tian, M.C., Zhang, G.M. \& Leng, X.L., Experimental and numerical investigations on the air-steam mixture bubble condensation characteristics in stagnant cool water. Nucl. Eng. Des., 285, pp. 188-196, 2015.

[18] Song, D., Erkan, N., Jo, B. \& Okamoto, K., Relationship between thermal stratification and flow patterns in steam-quenching suppression pool. Int. J. Heat Fluid Flow, 56, pp. 209-217, 2015.

[19] Xu, Q. \& Guo, L., Direct contact condensation of steam jet in crossflow of water in a vertical pipe. Experimental investigation on condensation regime diagram and jet penetration length. Int. J. Heat Mass Transf., 94, pp. 528-538, 2016.

[20] Qu, X.-H. \& Tian, M.-C., Acoustic and visual study on condensation of steam-air mixture jet plume in subcooled water. Chem. Eng. Sci., 144, pp. 216-223, 2016.

[21] Harby, K., Chiva, S. \& Muñoz-Cobo, J.L., Modelling and experimental investigation of horizontal buoyant gas jets injected into stagnant uniform ambient liquid. Int. J. Multiph. Flow, 93, pp. 33-47, 2017.

[22] Li, S.Q., Lu, T., Wang, L. \& Chen, H.S., Experiment study on steam-water direct contact condensation in water flow in a Tee junction. Appl. Therm. Eng., 2017.

[23] Li, W., Meng, Z., Wang, J. \& Sun, Z., Effect of non-condensable gas on pressure oscillation of submerged steam jet condensation in condensation oscillation regime. Int. J. Heat Mass Transf., 124, pp. 141-149, 2018.

[24] Li, W., Meng, Z., Sun, Z., Sun, L. \& Wang, C., Investigations on the penetration length of steam-air mixture jets injected horizontally and vertically in quiescent water. Int. J. Heat Mass Transf., 122, pp. 89-98, 2018.

[25] Dahikar, S.K., Sathe, M.J. \& Joshi, J.B., Investigation of flow and temperature patterns in direct contact condensation using PIV, PLIF and CFD. Chem. Eng. Sci., 65(16), pp. 4606-4620, 2010.

[26] Choo, Y.J. \& Song, C.-H.H., PIV measurements of turbulent jet and pool mixing produced by a steam jet discharge in a subcooled water pool. Nuclear Engineering and Design, 240(9), pp. 2215-2224, 2010.

[27] Cordova, Y., Rivera, Y., Blanco, D., Berna, C., Muñoz-Cobo, J.L. \& Escrivá, A., Experimental investigation of submerged horizontal air-steam mixture jets into stagnant water. Adv. Fluid Mech. XIII, 1, pp. 89-101, 2020.

[28] Liang, K.S. \& Griffith, P., Experimental and analytical study of direct contact condensation of steam in water. Nucl. Eng. Des., 147(3), pp. 425-435, 1994. 
[29] Zhao, Q., Cong, Y., Wang, Y., Chen, W., Chong, D. \& Yan, J., Effect of noncondensation gas on pressure oscillation of submerged steam jet condensation. Nucl. Eng. Des., 305, pp. 110-120, 2016.

[30] $\mathrm{Xu}, \mathrm{Y} .$, Direct contact condensation with and without non condensing gas in a water pool. Purdue University, West Lafayette, 2004.

[31] Xiaoping, Y., Daotong, C., Jiping, L., Xiao, Z. \& Junjie, Y., Experimental study on the direct contact condensation of the steam-air mixture in subcooled water flow in a rectangular channel. Int. J. Heat Mass Transf., 88, pp. 424-432, 2015. 